\title{
ANÁLISE MULTITEMPORAL DO CLIMA URBANO EM PALMAS, ESTADO DO TOCANTINS - BRASIL
}

\section{MULTITEMPORAL ANALYSIS OF URBAN CLIMATE IN THE PALMAS, TOCANTINS STATE - BRAZIL}

Felipe David Georges Gomes ${ }^{1}$, Isabela Marega Rigolin Fuzeto ${ }^{1}$, Renata Pereira Prates ${ }^{2}$

\author{
${ }^{1}$ Universidade do Oeste Paulista - UNOESTE, Presidente Prudente, SP. \\ ${ }^{2}$ Universidade Estadual Paulista - UNESP. \\ E-mail: felipedgg@yahoo.com.br
}

RESUMO - As alterações climáticas urbanas, provocadas pelo intenso adensamento urbano ocasionam perda de qualidade de vida. Assim, se faz cada vez mais necessário conhecer a dinâmica climática de determinada região em busca de estratégias para promoção de qualidade socioambiental. $O$ presente trabalho teve como objetivo analisar as variações espaço temporais do clima urbano e as implicações da disponibilidade hídrica e do NDVI nas ilhas de calor urbano. Para isso adotamos como estudo de caso o município de Palmas - Tocantins. Foi realizada a caracterização climatológica da área de estudo por meio do balanço hídrico climatológico proposto por Thornthwaite e Mather (1955), realizamos também cálculos da temperatura de superfície terrestre (LST) e do índice de vegetação por diferença normalizada (NDVI) por meio de imagens multiespectrais dos satélites LANDSAT7 e LANDSAT8 e de software de SIG. A partir do balanço hídrico climatológico foi possível constatar índices característico do clima tropical, bem como a dinâmica climática da região. Notamos ainda, pequenas ilhas de calor superficiais diagnosticadas por meio de imagem de satélite no ambiente urbano com magnitude de até $15{ }^{\circ} \mathrm{C}$ em relação ao rural próximo, principalmente nos períodos mais secos. Confirmamos ainda importância das áreas verdes na amenização das temperaturas terrestres.

Palavras-chave: Sensoriamento remoto; Balanço hídrico; Ilha de calor urbano.

ABSTRACT - The urban climate changes, caused by intense urban densities, result in loss life quality. Therefore, it becomes increasingly necessary to know the dynamics climatic of a given region in search of strategies to promote socio-environmental quality. The present work aimed to analyze the temporal space variations of the urban climate and the implications of water availability and NDVI in urban heat islands. For this purpose, we adopt as case study the municipality of Palmas - 
Tocantins. In a first moment, the climatological characterization of the study area through the climatological water balance proposed by Thornthwaite and Mather (1955) was carried out. Then the terrestrial surface temperature (LST) and Normalized Difference Vegetation Index (NDVI) were calculated by means of multispectral images of the LANDSAT7 and LANDSAT8 satellites and GIS software. From the climatic water balance, it was possible to verify indices characteristic of the tropical climate as well as the climatic dynamics of the region. We observed small surface heat islands diagnosed by means of satellite imagery in the urban environment with a magnitude of up to $15^{\circ}$ Celsius in relation to the nearby rural areas, especially in the drier periods. We also confirmed the importance of green areas in the mitigation of land temperatures.

Keywords: Remote sensing; Climatological water balance; Urban heat island.

\section{INTRODUÇÃO}

O clima é um elemento significativo na formação do ambiente planetário, sendo um objeto de interesse comum a pesquisadores que desejam contribuir na área ambiental (MENDONÇA, 2000). Para o mesmo autor no último quarto do século $X X$, o debate acerca das questões ambientais tem inserido em suas pautas o clima na interação sociedade-natureza. Para discutir tais questões devemos obrigatoriamente considerar a compreensão a respeito das escalas geográficas do clima, visando as análises das relações espaço-temporais.

Nessa perspectiva, Sant'Anna Neto (2013) aponta que desde as escalas globais às locais, os processos físico-naturais e de origem socioeconômica, interferem e determinam as características por meio das quais o clima se articula com o espaço geográfico. Para o autor, a sociedade tem demonstrado ser capaz de transformar as paisagens naturais numa velocidade crescente, indicando alterações que implicam na produção de climas antrópicos.

Paralelamente, Amorim

salienta que nos estudos de clima urbano, a perspectiva sistêmica permite entender as ações humanas no comportamento do clima. Alinhado a este pensamento, Moreira (1976) aponta que a cidade gera um clima próprio, resultante da interferência de todos os fatores que se processam sobre a camada do limite urbano e que agem alterando o clima em escala local. As cidades não só transformam o meio natural como também comprometem a qualidade dele. Isso se dá principalmente pelo crescimento urbano que ocorre sem a implantação de infraestrutura adequada (AMORIM, 2013). Muita desta falta de infraestrutura se deve as normas técnicas que na maioria das vezes são prescritas com base em regiões temperadas (MENDONÇA; MONTEIRO, 2009). Os mesmos autores explanam que a materialidade e as atividades do espaço urbano alteram o balanço energético, térmico e hídrico, criando condições climáticas dispares das áreas não urbanizadas.

Estudos como os de Youngsteadt et al. (2016), Porangaba et al. (2017), Yao (2017), Pomerantz (2018) e Sobstyl et al. (2018) demonstram a importância que as ilhas de calor têm sobre o clima urbano, por serem as mais percebidas pela população urbana. As ilhas de calor estão intimamente relacionadas a percepção humana e influenciam desde o desempenho físico para atividades habituais até graves problemas na saúde humana (PORANGABA et al., 2017). 
Essas alterações climáticas no setor intraurbano além de provocarem perda de qualidade de vida, principalmente à população com alta vulnerabilidade social, podem provocar outras alterações climáticas, como a alteração no comportamento das precipitações, apontada por Bernardes \& Mendes (2012).

Figura 1. Localização do município de Palmas - TO.

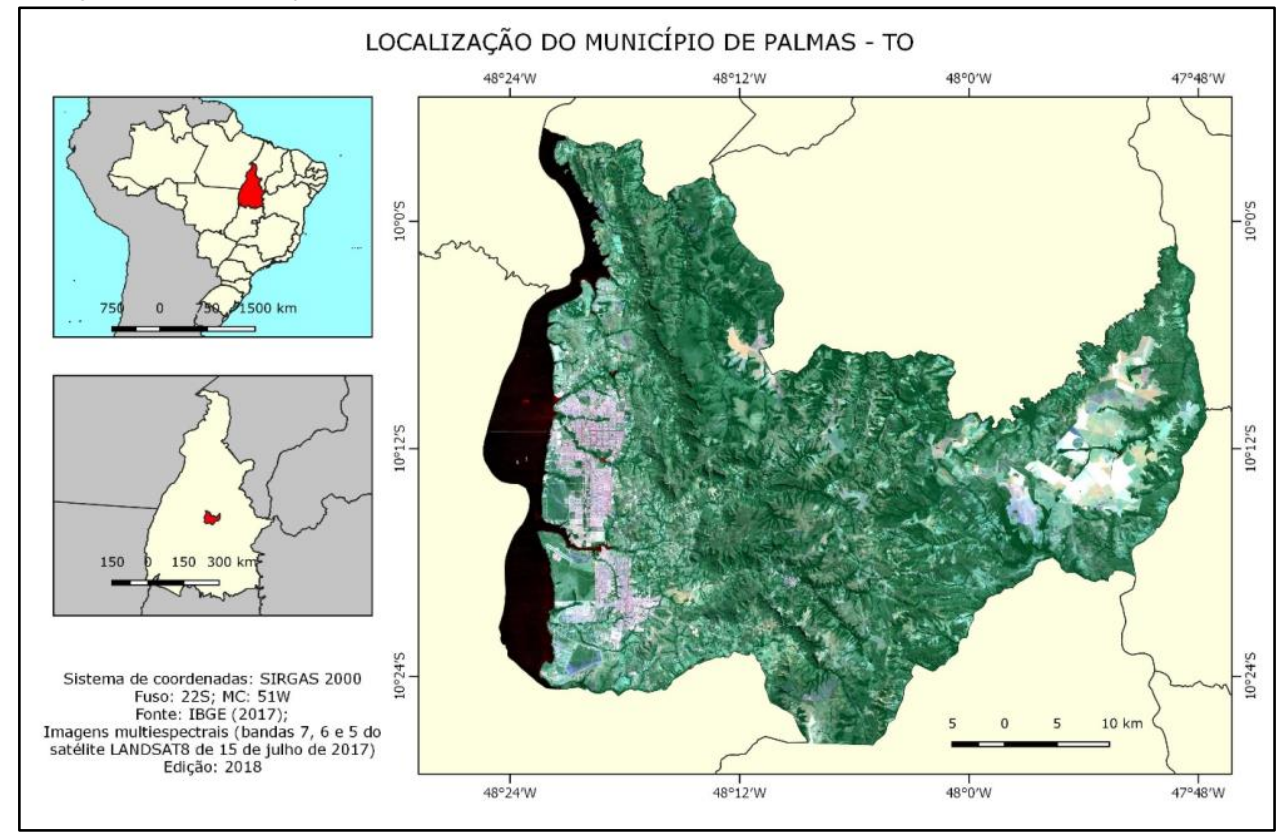

Diante do exposto e da importância em conhecer a dinâmica climática de determinada região para delinear um planejamento urbano adequado e promover qualidade socioambiental, o presente trabalho teve como objetivo analisar as variações espaço temporais do clima urbano, bem como as implicações da disponibilidade hídrica e do NDVI nas ilhas de calor urbanas de superfície, através de um estudo de caso em Palmas - Tocantins.

\section{2. ÁREA DE ESTUDO}

O município de Palmas está localizado no Norte do país, na região central do estado de Tocantins (Figura 1). Sua construção teve início no ano de 1989, e passou efetivamente a ser ocupado no ano de 1990. Seus limites abrangem uma área de $2.219 \mathrm{Km}^{2}$, que abarca uma população estimada em 291.855 habitantes (IBGE, 2018). Tal área fica entre a Serra do Lajeado e a margem direita do Rio Tocantins, composta por um planalto residual, constituído por arenito (SOUZA, 2010) e a cerca de $260 \mathrm{~m}$ acima do nível do mar.
A partir do ano de 2002, Palmas passou a ser margeada pelo reservatório da usina hidrelétrica "Luís Eduardo Magalhães", a Oeste do município, região onde também está concentrada a malha urbana municipal, como pode ser observado na Figura 1.

A partir de pesquisas bibliográficas percebe-se alguns poucos estudos (PAZ, 2009; SOUZA, 2011; FREITAS E PHELLIP, 2017; LIMA, 2018) referentes à característica climática desta região tropical de clima secoquente e úmido-quente. Em seu estudo sobre a região, Paz (2009) destaca que as densidades urbanas e populacionais aliadas aos elementos ambientais e climáticos influenciam diretamente o clima na cidade de Palmas. Enfatiza ainda que a urbanização implementada em conjunto com o adensamento de certas áreas, contribui para as alterações de temperatura.

\section{PROCEDIMENTOS METODOLÓGICOS}

Para realização do presente estudo foi atribuída uma escala temporal de 17 anos (2000 a 2017) e os procedimentos metodológicos basearam-se em três etapas 
principais: Caracterização climatológica da área de estudo, estimativa da temperatura de superfície terrestre (LST) e estimativa do índice de vegetação por diferença normalizada (NDVI).

A caracterização climática da área de estudo foi sintetizada por meio da estimativa do balanço hídrico climatológico (BHC). Estimamos o BHC anual para o período de 2000 a 2017 e o BHC normal mensal para os anos de 2000 e 2017. Utilizamos o método proposto por Thornthwaite e Mather (1955). Esse método considera a entrada de água no sistema representada pela precipitação, e a demanda atmosférica (retirada de água) representada pela evapotranspiração potencial, que é estimada pelo método de Thornthwaite (1948). A partir da capacidade de água disponível apropriada ao tipo de solo (125 mm), o método permite estimar os valores: de disponibilidade e de alteração do armazenamento de água do solo, de evapotranspiração real, de deficiência hídrica e de excedente hídrico (PEREIRA et al., 2007).

Para realização dos cálculos fizemos a compilação de dados de temperatura e precipitação dos anos 2000 a 2017 da página online

Giovanni

(https://giovanni.gsfc.nasa.gov/giovanni/),

cuja interface permite aos usuários analisar dados em grade da National Aeronautics and Space Administration (NASA) a partir de várias observações de satélite e de superfície. Os dados de temperatura do ar foram obtidos pela plataforma Modern-Era Retrospective analysis for Research and Applications (MERRA-2 Model) e os de precipitação pela plataforma Tropical Rainfall Measuring Mission (TRMM). Para a obtenção dos dados referentes a área de estudo a página online solicita uma caixa delimitadora, assim utilizou-se como caixa delimitadora as latitudes $-10,4^{\circ}$ a $-10,0^{\circ}$ e longitude de $-48,5^{\circ}$ a $-48,1$.

A estimativa das temperaturas de superfície terrestre, foram obtidas por meio de imagens dos satélites LANDSAT7 e LANDSAT8, para os anos de 2000 e 2017, respectivamente. A captura das imagens data de 05 de maio e 08 de julho de 2000 e 15 de julho de 2017. As imagens foram obtidas gratuitamente na página online da United States Geological Survey (USGS) (http://earthexplorer.usgs.gov/). As bandas utilizadas foram as do canal infravermelho termal. Para o satélite LANDSAT7 a banda utilizada foi a de número 6 , cuja resolução espectral é de 10,31 - 12,36 $\mu \mathrm{m}$ e a resolução espacial 60 metros (reamostrada para $30 \mathrm{~m}$ ). Já para o satélite LANDSAT8 a banda do infravermelho termal utilizada, corresponde a de número 10 , com resolução espectral de 10,6 - 11,19 $\mu \mathrm{m}$ e resolução espacial de 100 metros (reamostrada para 30 $\mathrm{m})$.

O tratamento das imagens teve início com o cálculo da radiância espectral do topo da atmosfera, realizado com o auxílio de um software de Sistema de Informação Geográfica (SIG) e da equação que se segue, disponibilizada na USGS.

$$
L_{\lambda}=M_{L} * Q_{c a l}+A_{L}
$$

Onde:

$L_{\lambda}=$ Radiância espectral $\left(\mathrm{W} / \mathrm{m}^{2} \cdot \mathrm{sr} \cdot \mu \mathrm{m}\right)$

$M_{L}=$ Fator multiplicativo de redimensionamento de cada banda presente nos metadados (Radiance_Mult_Band_x, onde x é o número da banda);

$$
A_{L}=\text { Fator aditivo de }
$$

redimensionamento de cada banda presente nos metadados (Radiance_Add_Band_x, onde x é o número da banda);

$Q_{c a l}=$ Valores de pixel quantificados e calibrados do produto padrão (DN).

Ainda com o auxílio de um software de SIG, a radiância espectral foi convertida para temperatura em Kelvin (K) e sequencialmente convertida para graus Celsius $\left({ }^{\circ} \mathrm{C}\right)$. A radiância do topo da atmosfera foi convertida em temperatura (K) por meio da seguinte equação:

$$
T=\frac{K_{2}}{\ln \left(\frac{K_{1}}{L_{\lambda}}+1\right)}
$$


Onde:

$T=$ Temperatura efetiva no satélite em Kelvin;

$K_{1}=$ Constante de calibração 1 , presente nos metadados;

$K_{2}=$ Constante de calibração 2, presente nos metadados.

A conversão para ${ }^{\circ} \mathrm{C}$ foi realizada através da subtração de 273,15 dos valores das temperaturas em $\mathrm{K}$ obtidos para cada pixel. Vale salientar que os valores dos fatores multiplicativos $(0,067087 \quad-$ LANDSAT7 e 0,0003342 - LANDSAT8), dos fatores aditivos $(-0,06709$ - LANDSAT7 e 0,1000 - LANDSAT8) e das constantes de calibração ((K1=666,09 e K2=1282,71 LANDSAT7) e (K1=774,89666 e K2=1321,08 LANDSAT8)) são encontrados nos metadados das imagens a serem utilizadas.

Para facilitar as comparações entre os mapas de temperatura optou-se pela representação por meio da intensidade. Adotou-se o método utilizado por Amorim (2017), onde o pixel com o menor valor de temperatura da cena foi adotado como ponto "zero", a partir desse valor as diferenças de temperaturas dos alvos (por pixel), foram calculadas com o intuito de reconhecer um padrão de aquecimento nos ambientes intraurbanos e rurais próximos.

Encontradas as intensidades das diferenças de temperaturas de superfície e a fim de verificar possíveis alterações de temperatura em razão da supressão e/ou aumento da cobertura vegetal na escala temporal adotada, mapas de NDVI foram gerados. O NDVI é um índice proposto por Rouse et al. (1974), a partir da normalização do índice de vegetação da razão simples. Este índice permiti identificar a densidade e a distribuição vegetal, a partir de um intervalo que varia de $-1 \mathrm{a}+1$, sendo que quanto mais próximo de 1 maior a densidade vegetal. A equação utilizada por meio de software de SIG é a seguinte:

$$
N D V I=\frac{\rho_{N I R}-\rho_{R E D}}{\rho_{N I R}+\rho_{R E D}}
$$

Onde

$N D V I=$ Índice de vegetação;

$\rho_{N I R}=$ Valores de refletância no espectro infravermelho próximo;

$\rho_{R E D}=$ Valores de refletância no espectro vermelho.

Figura 2. Dinâmica meteorológica de 2000 e 2017 e características climáticas de 2000-2017

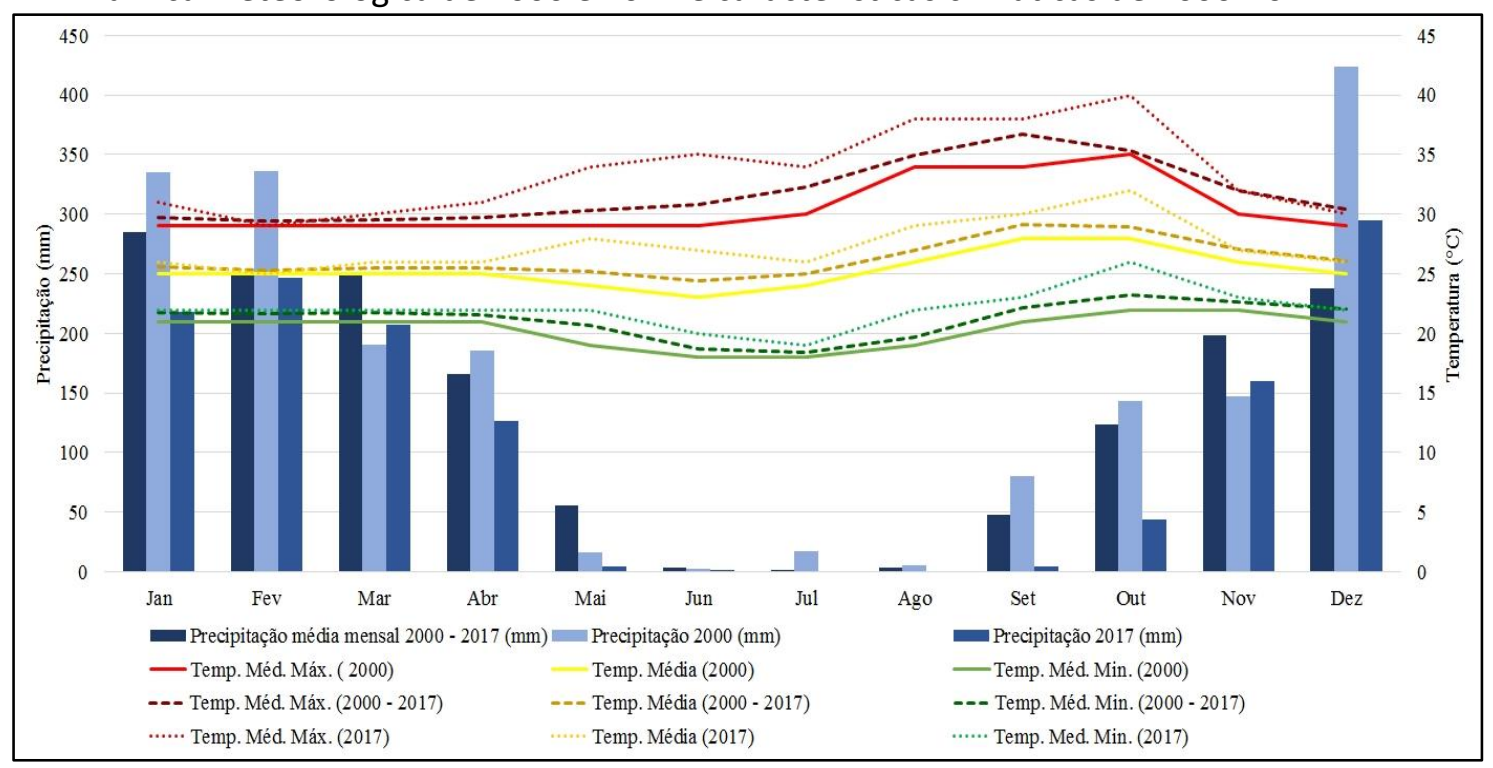


Vale salientar que foi realizado um recorte para análise do intraurbano e rural próximo a partir da sobreposição das bases cartográficas do setor censitário, disponibilizadas pelo IBGE.

\section{RESULTADOS E DISCUSSÕES}

Comparando os dados meteorológicos (Figura 2) da escala temporal adotada (20002017) com os dados do ano inicial (2000) e final (2017), nota-se que as temperaturas mínimas, médias e máximas para o ano de 2000 estão abaixo da média calculada para os anos de 2000 a 2017, e as do ano de 2017 estão acima, demonstrando um período mais quente. Pode-se associar essas temperaturas um pouco mais amenas no ano de 2000 em comparação aos outros dois períodos em função do volume de precipitação. No ano 2000 o volume de precipitação na maioria dos meses (janeiro, fevereiro, abril, julho, agosto, setembro outubro e dezembro) foram maiores que os registrados para 2017 e para a média do período de 2000 a 2017. Nos meses de janeiro, fevereiro, abril, julho, agosto, setembro e outubro, os volumes de precipitação para 2000 foram maiores que a média da escala temporal e os volumes de precipitação de 2017 menores.

Observa-se que a média das temperaturas são maiores nos meses de agosto, setembro e outubro (final do inverno a meados da primavera) (Figura 2). Houve variação da temperatura mínima e máxima entre os anos de $2000\left(17,8^{\circ} \mathrm{C}\right.$ - julho e 35,1 ${ }^{\circ} \mathrm{C}$ - outubro) e $2017\left(19,4^{\circ} \mathrm{C}\right.$ - julho e $39,7^{\circ} \mathrm{C}$ - outubro) de $1,6{ }^{\circ} \mathrm{C}$ para as mínimas e de $4,6^{\circ} \mathrm{C}$ para as máximas. A amplitude de temperatura do ano 2000 foi de $17,3^{\circ} \mathrm{C}$, já para 2017 a amplitude atingiu $20,3{ }^{\circ} \mathrm{C}$, totalizando uma diferença de $3{ }^{\circ} \mathrm{C}$. Em relação à média calculada para o período de 2000 a 2017 a máxima $\left(36,7^{\circ} \mathrm{C}\right)$ registrada foi em setembro e a mínima $\left(18,4^{\circ} \mathrm{C}\right)$ em julho, cuja amplitude foi $18,3^{\circ} \mathrm{C}$.

Tabela 1. Balanço Hídrico Climatológico para Palmas, TO (2000 - 2017).

\begin{tabular}{c|c|c|c|c|c|c}
\hline Meses & $\mathbf{T}\left({ }^{\circ} \mathrm{C}\right)$ & $\mathbf{P}(\mathrm{mm})$ & $\mathbf{E T P}(\mathrm{mm})$ & $\mathbf{E T R}(\mathbf{m m})$ & $\mathbf{D E F}(\mathbf{m m})$ & $\mathbf{E X C}(\mathbf{m m})$ \\
\hline JAN & 25,6 & 285,5 & 142,2 & 142,2 & 0,0 & 143,3 \\
\hline FEV & 25,3 & 249,6 & 110,7 & 110,7 & 0,0 & 138,9 \\
\hline MAR & 25,5 & 251,0 & 136,5 & 136,5 & 0,0 & 114,5 \\
\hline ABR & 25,5 & 165,5 & 131,4 & 131,4 & 0,0 & 34,1 \\
\hline MAI & 25,2 & 55,8 & 156,8 & 125,1 & 31,7 & 0,0 \\
\hline JUN & 24,4 & 3,3 & 139,1 & 40,2 & 98,9 & 0,0 \\
\hline JUL & 25,0 & 1,3 & 127,5 & 13,2 & 114,3 & 0,0 \\
\hline AGO & 27,0 & 3,2 & 183,5 & 8,4 & 175,1 & 0,0 \\
\hline SET & 29,1 & 47,5 & 191,8 & 48,6 & 143,2 & 0,0 \\
\hline OUT & 29,0 & 123,7 & 251,7 & 124,1 & 127,6 & 0,0 \\
\hline NOV & 27,1 & 198,2 & 148,9 & 148,9 & 0,0 & 0,0 \\
\hline DEZ & 26,1 & 238,1 & 140,6 & 140,6 & 0,0 & 22,0 \\
\hline ANO & $\mathbf{2 6 , 2}$ & $\mathbf{1 6 2 2 , 6}$ & $\mathbf{1 8 6 0 , 6}$ & $\mathbf{1 1 6 9 , 9}$ & $\mathbf{6 9 0 , 7}$ & $\mathbf{4 5 2 , 7}$ \\
\hline
\end{tabular}

$\mathrm{T}=$ Temperatura do ar; $\mathrm{P}=$ Precipitação; ETP = Evapotranspiração Potencial; ETR = Evapotranspiração real; DEF = Deficiência Hídrica e EXC = Excedente Hídrico

Observa-se que para o período em estudo a precipitação total média anual foi de 1622,6 mm (Tabela 1), tendo uma distribuição bastante irregular ao longo do ano, sendo evidenciando dois períodos distintos, um chuvoso (entre os meses de outubro e abril) que contribui com $93 \%$ do volume pluviométrico anual e outro seco (entre os meses de maio e setembro) e representa pouco menos de $7 \%$ do total médio anual. 
Nota-se que a evapotranspiração potencial (ETP) varia pouco ao longo do ano, fato associado a temperaturas médias mensais altas. A deficiência hídrica (DEF) ocorreu durante o período de maio a outubro, totalizando $690,7 \mathrm{~mm}$. Por sua vez foi observado que o período de dezembro a abril, teve excedentes hídricos (EXC), que totalizou $452,7 \mathrm{~mm}$.

Quando analisado o extrato do balanço hídrico anual entre os anos de 2000 e 2017 (Figura 3) observa-se que o ano inicial da escala temporal (2000) estava entre os períodos mais chuvosos $(1881,8 \mathrm{~mm})$ com um excedente hídrico de $446 \mathrm{~mm}$ e que o ano de 2017 (último na escala temporal definida) estava entre um dos períodos mais seco $(1307,1 \mathrm{~mm})$, registrando déficit hídrico de $606 \mathrm{~mm}$. Assim, vale salientar que as variáveis do balanço hídrico afetam as atividades biológicas e socioeconômicas, visto que irregularidades pluviométricas, concentrações em curtos períodos e altas taxas de evapotranspiração acarretam baixa disponibilidade para atividades essenciais (DE SANTOS \& DE AQUINO, 2016). Da mesma forma quando ocorre altas taxas de precipitação, concentradas ou não em um curto período de tempo, outros danos são causados.

Figura 3. Extrato do balanço hídrico anual de 2000 a 2017.

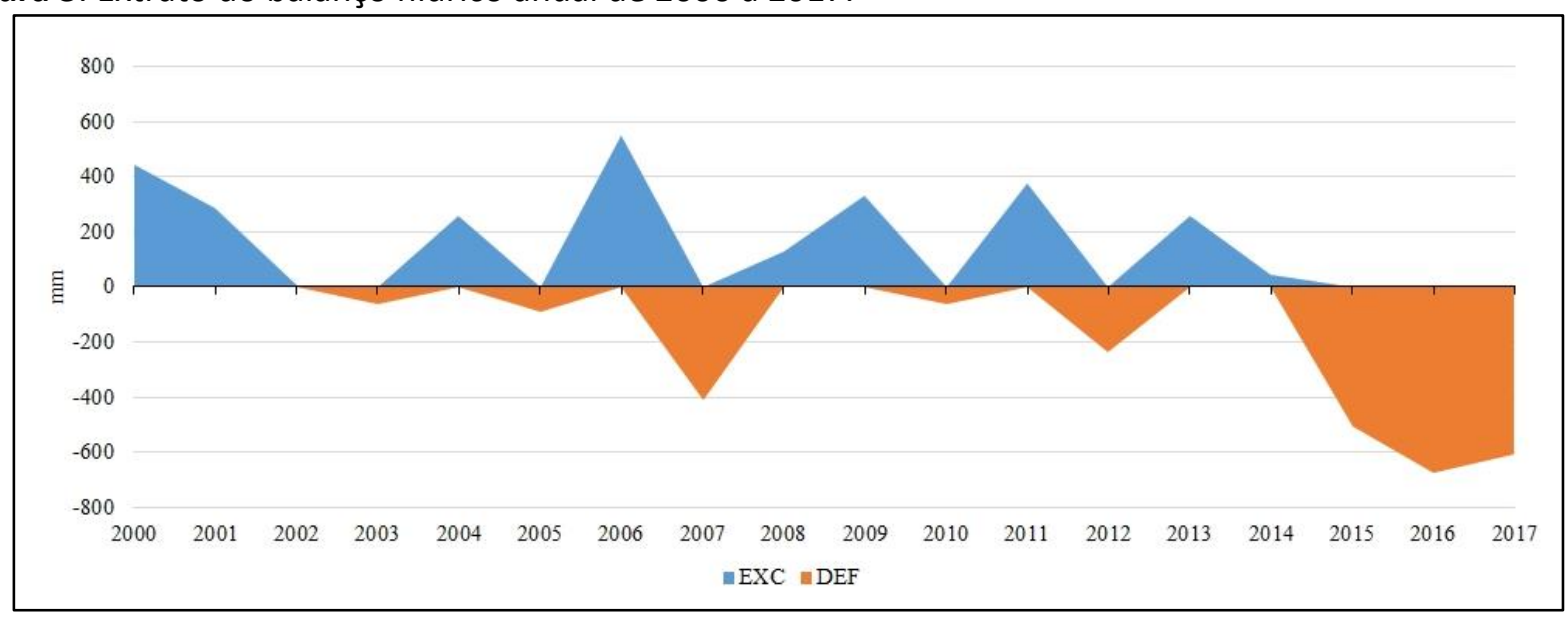

Na figura 4 observa-se que o volume de precipitação mensal do ano de 2000 variou de $2,0 \mathrm{~mm}$ a $423,9 \mathrm{~mm}$ e do ano de 2017 de $0,0 \mathrm{~mm}$ a 295,0 mm. Em ambos os anos os meses mais chuvosos se concentram entre as estações primavera-verão e os mais secos entre o outono-inverno. Resultados similares são apresentados por Guarda (2006), chamando atenção em sua pesquisa para o comportamento sazonal marcante da evaporação, que segue um padrão inverso ao da precipitação. Como pode ser observado na Figuras 4 e 5, tanto para o ano de 2000 como para o de 2017 a evapotranspiração potencial é maior nos períodos de menor índices pluviométricos.

Figura 4. Precipitação (mm) e evapotranspiração potencial e real para os anos de 2000 e 2017.

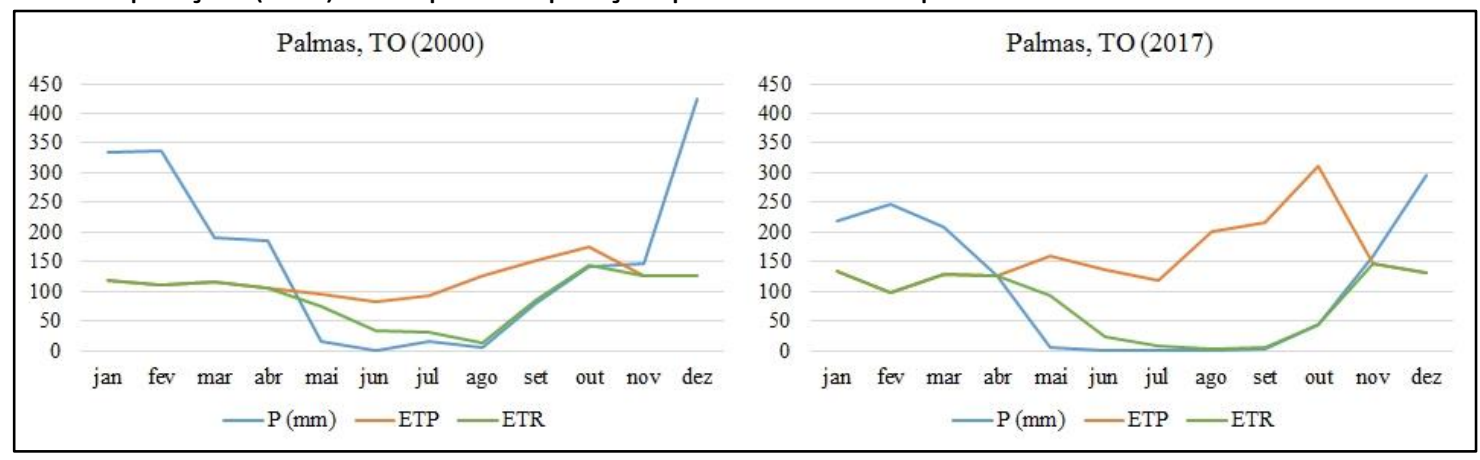


Figura 5. Deficiência, excedente, retirada e reposição hídrica para os anos de 2000 e 2017.

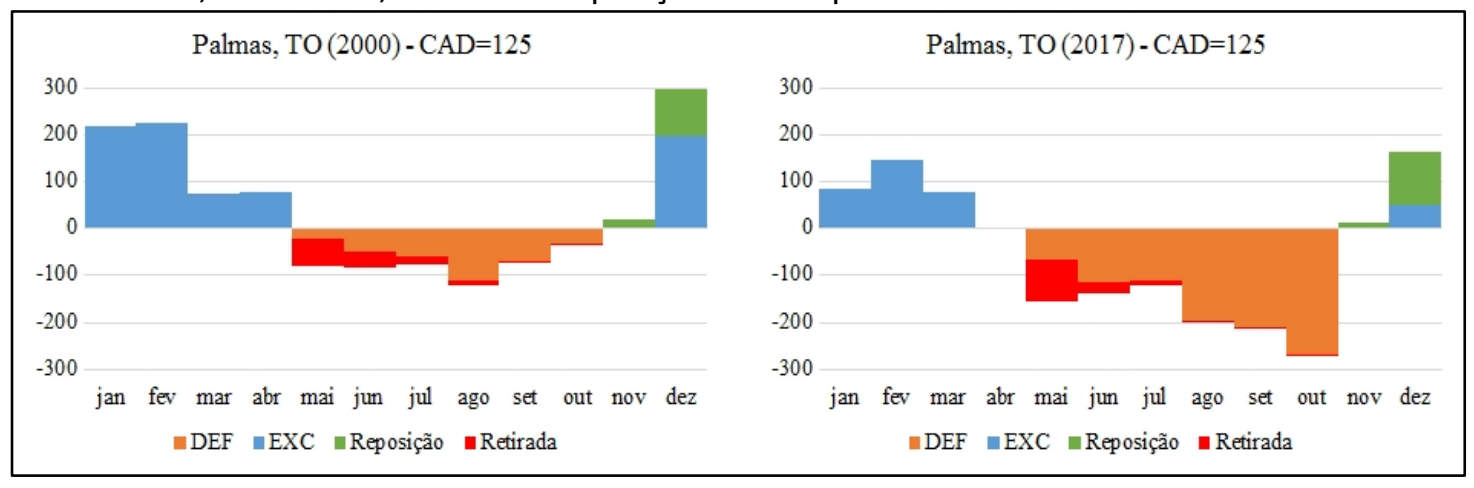

$\mathrm{Na}$ imagem de maio de 2000 é possível observar que as repostas espectrais dos alvos receberam influência de um período de excedentes hídricos (abril - 78,1 $\mathrm{mm})$, possibilitando visualizar de que maneira o balanço hídrico climatológico afeta a dinâmica da diferença de temperaturas.

Verificou-se que a intensidade da variação das temperaturas foi maior quando comparada as do ano de 2017 (Figura 6). Essas variações com intensidade mais alta $\left(13,0\right.$ a $\left.15,0{ }^{\circ} \mathrm{C}\right)$ se encontram próximas as áreas com adensamento urbano maior. Notou-se ainda em ambas as imagens, que as temperaturas mais baixas se situam próximas a hidrografia do município.

$O$ fato das menores temperaturas serem registradas apenas em pequenas áreas possivelmente se deve ao fato de em ambas as imagens a temperatura de superfície ter sido gerada a partir de imagens de satélite capturadas em período de déficit hídrico, e em horário do meio da manhã. Resultados similares são apresentados no estudo de Amorim e Dubreuilt (2017), onde os autores observaram redução do albedo das superfícies de solo exposto e a retenção de mais calor. Outro fator a ser considerado é o aumento da disponibilidade hídrica para a região, com o reservatório da usina hidrelétrica visto na imagem do ano de 2017, já que o a umidade do ar afeta a intensidade da variação de temperatura do intraurbano com o rural próximo. 
Figura 6. Intensidade da variação das temperaturas de superfície terrestre para os anos de 2000 e 2017.

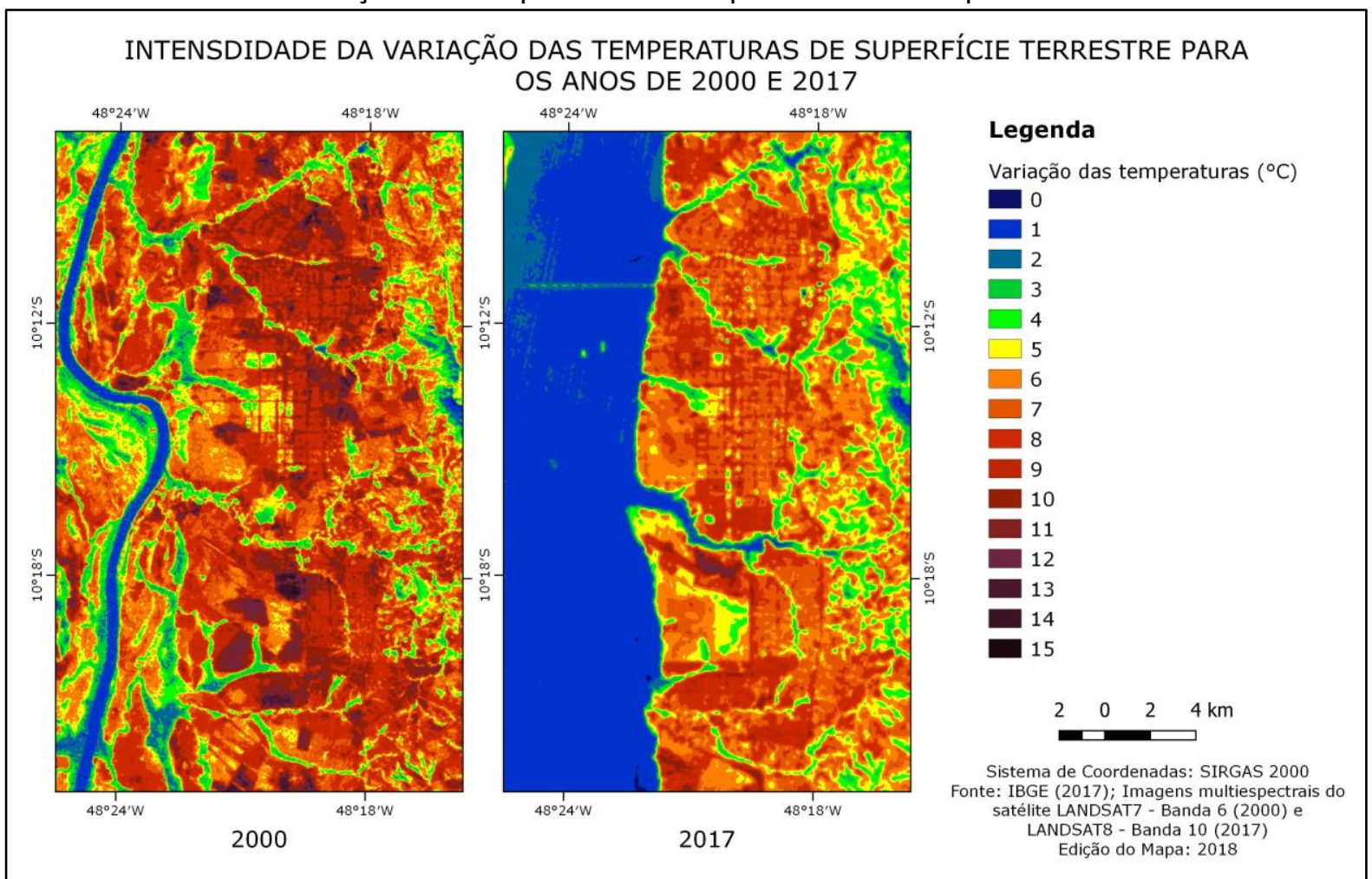

Em função da formação do lago da Usina "Luis Eduardo Magalhães" (que abrange o município de Palmas) no ano de 2001, optou-se por estimar a temperatura de superfície e o índice de vegetação por diferença normalizada (NDVI) para o ano 2000 em períodos com influência de excedente hídrico e deficiência hídrica.

Assim, na comparação dos mapas da Figura 7, constatou-se que no período em que a imagem sofre influência de excedente hídrico (05 de maio) a área urbana densamente construída apresenta uma menor variação da intensidade de temperatura em relação as áreas rurais próximas. Nota-se ainda que no período de déficit hídrico (08 de julho) a amplitude na variação de temperatura entre os cursos hídricos e áreas densamente arborizadas em relação ao intraurbano é maior.

Através da comparação entre os mapas da Figura 7 e o balanço hídrico climatológico foi observado que o período de excedente hídrico propicia uma maior variabilidade da temperatura entre o rural próximo e o intraurbano. Isso ocorre pois no período de déficit hídrico a massa vegetal é reduzida e a umidade disponível no solo também diminui juntamente com o volume da evaporação e da evapotranspiração (AMORIM \& DUBREUILT, 2017). 
Figura 7. Intensidade das variações das temperaturas de superfície terrestre para o ano de 2000 em períodos de excedente (05 de maio) e déficit hídrico (08 de julho)

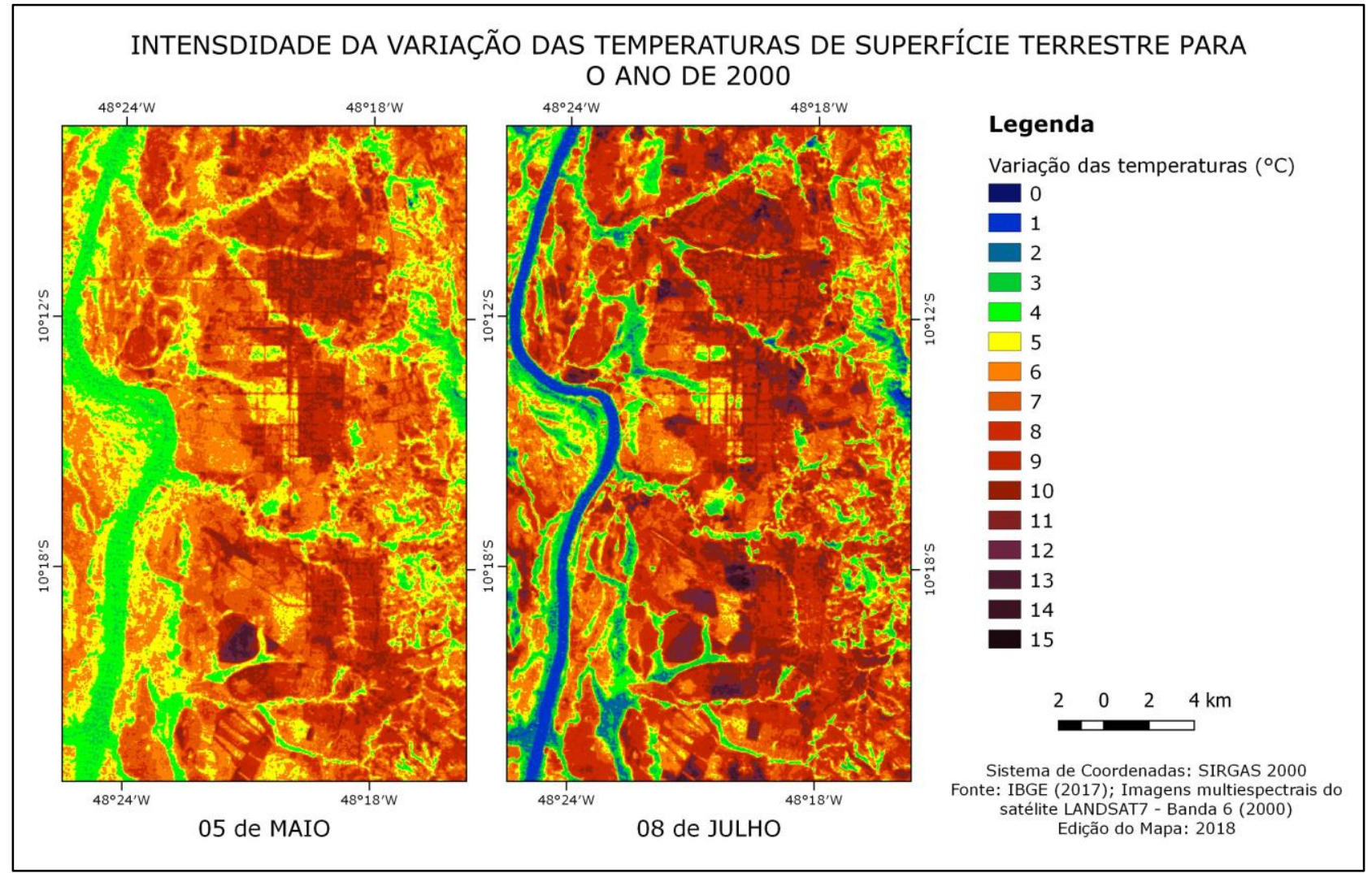

Verificou-se por meio da comparação entre os NDVIs do ano de 2000 que a imagem de satélite de 5 de maio possui uma maior densidade vegetal em relação a imagem de 8 de julho (Figura 8). Tal fato pode ser explicado pela disponibilidade de água para a vegetação. Essa disponibilidade afeta as taxas de fotossíntese (SANTOS \& CARLESSO, 1998), de modo que o déficit no balanço hídrico climatológico tem papel fundamental no decréscimo da produção da área foliar, do fechamento dos estômatos, da aceleração da senescência e da abscisão das folhas
(MCCREE; FERNÁNDEZ,1989); TAIZ \& ZEIGER (1991)). O processo fotossintético das plantas responsáveis é responsável pela resposta espectral da vegetação, assim, a medida que ocorre alterações morfo-fisiológicas no dossel, as frações absorvida, transmitida e refletida da radiação eletromagnética também são alteradas (RUSSEL et al., 1989; NOBEL et al., 1993). Diante disso, a menor densidade vegetal calculada para o período de déficit hídrico, pode estar relacionada com a resposta espectral das plantas, em processo de déficit hídrico. 
Figura 8. Índice de vegetação por diferença normalizada para os anos de 2000 e 2017

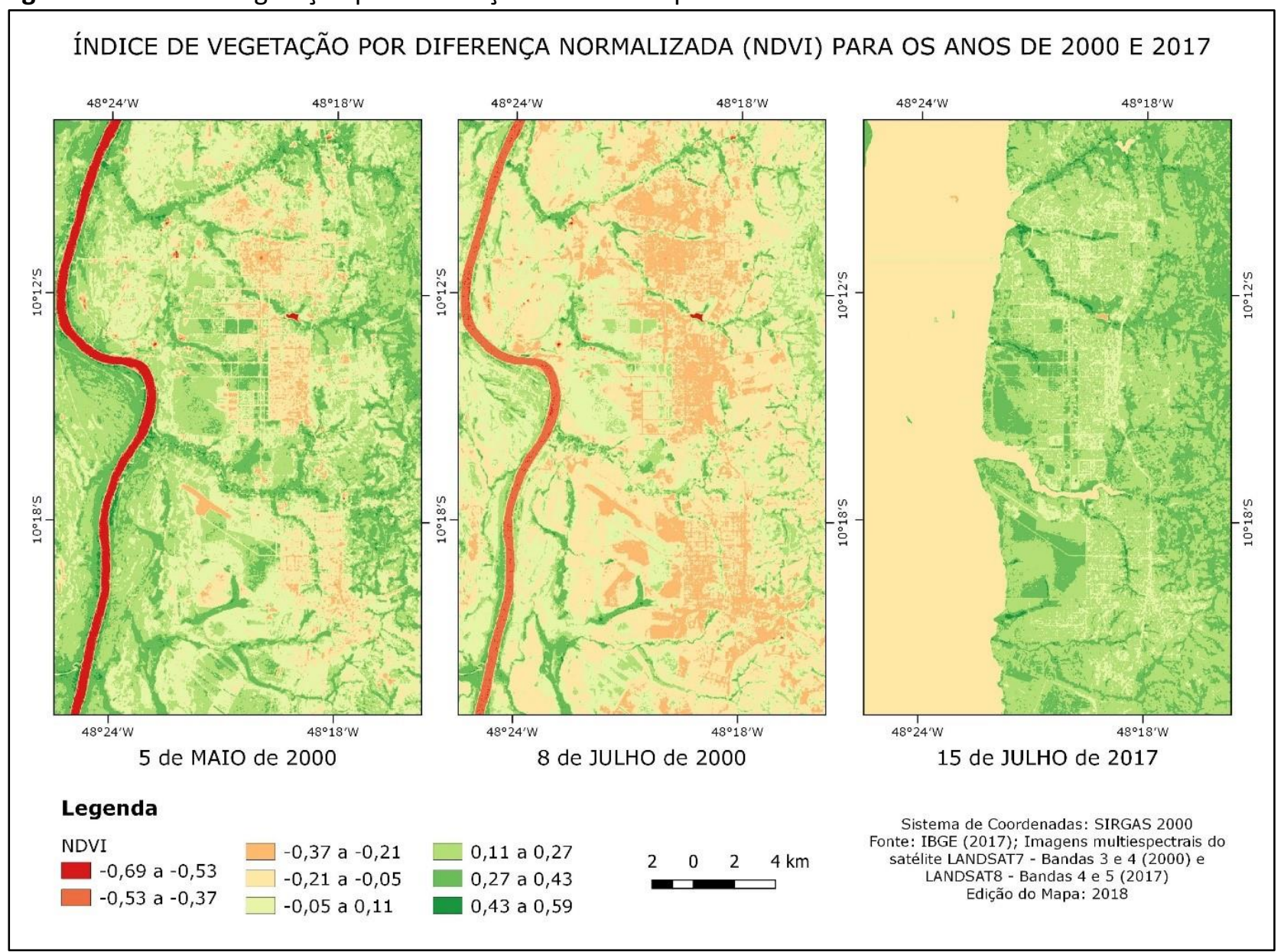

Na comparação entre os períodos de déficit hídrico de 2000 e 2017 observou-se maior densidade vegetativa no ano de 2017. Ressalta-se que a recente construção do município (10 de janeiro de 1990) e o represamento do Rio Tocantins, proporcionou o plantio de mudas arbóreas como medida de compensação ambiental. Devido a este fato e por meio da comparação entre os mapas, observa-se que no período de 2000 as áreas verdes urbanas de Palmas ainda estavam em processo de formação.

Por meio das figuras 6,7 e 8 observou-se as menores variações de temperatura encontradas nas cenas das imagens tratadas (de $0{ }^{\circ} \mathrm{C}$ a $3{ }^{\circ} \mathrm{C}$ ), que estão em áreas de cursos hídricos e com uma maior intensidade de vegetação arbórea (Figura 8). Estudos similares foram apontados por Amorim e Monteiro (2011), Pereira et al. (2012), Silva e Leite (2017) e Leite et al. (2018). O elevado calor específico da água, atenua a temperatura e dificulta o aumento da mesma (PRIMAVESI et al., 2007; PONZONI; SHIMABUKURO, 2009; JENSEN, 2010). Primavesi et al. (2007) aponta ainda que as plantas quando possuem disponibilidade hídrica, evapotranspiram em maior quantidade, lançando seus vapores e retirando o calor atmosférico.

Realizando a comparação dos mapas de intensidade das variações das temperaturas de superfície terrestre para os anos de 2000 e 2017, cujo balanço hídrico climático foi deficitário foi observado que embora as grandes variações de temperatura estejam reduzidas as áreas arborizadas e com cursos hídricos, a cidade apresenta variações mais elevadas (a partir de $10{ }^{\circ} \mathrm{C}$ ) na área densamente urbanizada do ano de 2000, explicada pelos menores índices de vegetação neste ano. 


\section{CONSIDERAÇÕES FINAIS}

A partir do balanço hídrico climatológico foi possível constatar índices característico do clima tropical, com períodos chuvosos na estação climática primaveraverão e secos entre o outono-inverno. Observou-se pouca variação entre as médias de temperatura, e que elas tiveram seus picos nos meses de agosto, setembro e outubro (final do inverno a meados da primavera).

Notou-se pequenas ilhas de calor superficiais diagnosticadas por meio de imagem de satélite no ambiente urbano com magnitude de até $15{ }^{\circ} \mathrm{C}$ principalmente nos períodos mais secos, sendopossível inferir através das análises que a formação do lago da usina hidrelétrica "Luís Eduardo Magalhães", bem como o aumento da densidade vegetal mostrada pelo NDVI, contribui para a amenização da intensidade da variação de temperatura entre o rural próximo e o intraurbano no ano de 2017.

Com relação ao índice de vegetação e a comparação entre a intensidade da variação das temperaturas de superfície, foi observado a importância das áreas verdes para amenização da temperatura.

Por fim, a partir das análises apresentadas, o delineamento de estratégias de gestão e de gerenciamento podem ser tomadas, visando o conforto térmico da população urbana. Em trabalhos futuros, recomendamos análises da temperatura do ar no período noturno, por meio da metodologia de transectos móveis aplicada primeiramente por Oke (1982). Outra sugestão é a associação da metodologia de Oke com a análise rítmica criada por Monteiro. Tais análise podem ajudar a entender melhor a dinâmica do clima urbano no município de Palmas - TO.

\section{REFERÊNCIAS}

AMORIM, M. C. T. A. Clima urbano: estrutura térmica e ilhas de calor. In: AMORIM, M. C. T. A.; SANT'ANNA NETO, J. L.; MONTEIRO, A. (Orgs.). Climatologia urbana e regional: Questões teóricas e estudos de caso. 1 ed.
São Paulo: Outras expressões, 2013. https://doi.org/10.18055/Finis6888

AMORIM, M. C. C. T. Detecção remota de ilhas de calor superficiais: Exemplos de cidades de porte médio e pequeno do ambiente tropical, Brasil. Finisterra-Revista Portuguesa de Geografia, n. 105, p. 111-133, 2017. https://doi.org/10.4000/confins.7284

AMORIM, M. C. C. T. ; MONTEIRO, A. As temperaturas intraurbanas: exemplos do Brasil e de Portugal. Confins. Revue francobrésilienne de géographie/Revista francobrasilera de geografia, n. 13, 2011.

AMORIM, M.; DUBREUIL, V. A interferência da precipitação na intensidade e na distribuição espacial das ilhas de calor de superfície nas estações do ano em ambiente tropical. In: SBSR, 18., 2017, Santos. Anais [...]. Santos: INPE, 2017.

BERNARDES, F. F.; MENDES, P. C. A urbanização e sua influência no aumento da temperatura média no município de Uberlândia/MG. Revista Geonorte, 2, v. 2, n. 5 (Ed. Esp.), p. 77 - 88, 2012.

BRASIL. IBGE. Censo demográfico: Palmas TO. Disponível em: https://cidades.ibge.gov.br/brasil/to/palmas/ panorama. Acessado em: 29 nov. 2018

DOS SANTOS, F. A. ; DE AQUINO, C. M. S.. Balanço hídrico climatológico dos municípios de Castelo do Piauí e Juazeiro do Piauí, Nordeste, Brasil. Revista Geoaraguaia, v. 6, n. 1, 2016.

FREITAS, F.; PHELLIP, T.. O campo térmico de Palmas/TO em episódios de primavera-verão e de outono-inverno: subsídio ao planejamento urbano. Boletim de Geografia, $\begin{array}{llll}\text { v. } 35, \quad \text { n. } 2, & 2017 .\end{array}$ https://doi.org/10.4025/bolgeogr.v35i2.3431 $\underline{7}$ GUARDA, S. D. M. Expansão urbana do entorno do lago do município de Palmas - 
TO (1990, 1993, 1999, 2002, 2005): Acompanhamento por dados de sensoriamento remoto. 2006. Dissertação (Mestrado) - Fundação Universidade Federal do Tocantins, Palmas, 2006.

JENSEN, J. R. Sensoriamento remoto do ambiente: uma perspectiva em recursos terrestres. São José dos Campos/SP: Parênteses, 2010. 597p.

LEITE, M. E. et al. Geotecnologias aplicadas a estimativa da temperatura de superfície em diferentes usos e ocupações do solo na Área de Proteção Ambiental do Rio PandeirosMinas Gerais. Caderno de Geografia, v. 28, n. 53, p. 490-509, 2018. https://doi.org/10.5752/P.2318-

2962.2018v28n53p490-509

LIMA, J. R. Dinâmica climática, queimadas e doenças respiratórias em Palmas-TO. Palmas, 2018.

McCREE, K. J.; FERNÁNDEZ, C. J. Simulation model for studyng physiological water stress responses of whole plants. Crop Science, Madison, v. 29, p. 353-360, 1989. https://doi.org/10.2135/cropsci1989.001118 $\underline{3 \times 002900020025 x}$

MENDONÇA, F. A. Aspectos da interação clima-ambiente-saúde humana: da relação sociedade-natureza à (in) sustentabilidade ambiental. Raega-O Espaço Geográfico em Análise, $\quad v$ v $\quad 4,2000$. https://doi.org/10.5380/raega.v4i0.3341

MENDONÇA, F.; MONTEIRO, C. A. F. (ed.). Clima urbano. 1 ed. São Paulo: Contexto, 2009.

MONTEIRO, C. A. de F. Teoria e clima urbano. Série Teses e Monografias, São Paulo: USP/Igeog, n.25, 1976, 181p.

MONTEIRO, C. A. F. Análise rítmica em climatologia - problemas da atualidade climática em São Paulo e achegas para um programa de trabalho. Climatologia 1, São Paulo, n. 1, 1971. 21 p.

NOBEL, P.S.; FORSETH, I.; LONG, S.P. Canopy structure and light interception. In: HALL, D.O.; SCURLOCK, H.R.; BOLHÀRNORDENKAMPF; LEEGOOD, R.C.; LONG, S.P. Photosynthesis and production in a changing environment. London: Chapman \& Hall, 1993.

p. 79-90. https://doi.org/10.1007/978-94-011-156676

OKE, T.R. The energetic basis of the urban heat island. Quarterly Journal of the Royal Meteorological Society, v. 108 , n. 455 , p. 124, jan. 1982.

https://doi.org/10.1256/smsqj.45501

PAZ, Luis Hildebrando Ferreira. A influência da vegetação sobre o clima urbano de Palmas-TO. Brasília - DF: Universidaded de Brasília, 2009. (Disertação de mestrado)

PEREIRA, A. R. et al. Meteorologia agrícola. Universidade de São Paulo, ESALQ: Piracicaba, SP, 2007.

PEREIRA, Clarissa Cardoso et al. Análise da temperatura de superfície e do uso da terra e cobertura vegetal na bacia barra dos coqueiros (Goiás). Revista Geonorte, 2, v. 2, n. 5, p. $1243-1255$ (Ed. Esp.), 2012.

POMERANTZ, Melvin. Are cooler surfaces a cost-effect mitigation of urban heat islands?. Urban climate, v. 24, p. 393-397, 2018. https://doi.org/10.1016/j.uclim.2017.04.009

PONZONI, F. J.; SHIMABUKURO, Y. E. Sensoriamento remoto no estudo da vegetação. São José dos Campos, SP: A. Silva Vieira, 2009.

PORANGABA, G. F. O. ; TEIXEIRA, D. C. F. ;AMORIM, M. C. C. T. Procedimentos Metodológicos para análise das ilhas de calor em cidades de pequeno e médio porte. Revista Brasileira de Climatologia, v. 21, 
2017.

https://doi.org/10.5380/abclima.v21i0.48832

PRIMAVESI, O.; ARZABE, C.; PEDREIRA, M. S.; Mudanças climáticas: visão tropical integrada das causas, dos impactos e de possíveis soluções para ambientes rurais ou urbanos. São Carlos: Embrapa Pecuária Sudeste, 2007.

ROUSE, J.W., HAAS, R.H., SCHELL, J.A. and DEERING, D.W. Monitoring vegetation systems in the Great Plains with ERTS. In 3rd ERTS Symposium, NASA SP-351 I, pp. 309317, 1973.

RUSSEL, G.; JARVIS, P. G.; MONTEITH, J.L. Absorption of radiation by canopies and stand growth. IN: RUSSEL, G.; MARSHALL, B.; JARVIS, P.G. Plant canopies: their growth, form and function. Cambridge: Cambridge University Press, $1989 . \quad$ p. 21-39. https://doi.org/10.1017/CBO9780511752308 .003

SANT'ANNA NETO, J. L. Escalas geográficas do clima: mudança, variabilidade e ritmo. In: AMORIM, M. C. T. A.; SANT'ANNA NETO, J. L.; MONTEIRO, A. (org..). Climatologia urbana e regional: Questões teóricas e estudos de caso. 1 ed. São Paulo: Outras expressões, 2013.

SANTOS, Reginaldo Ferreira; CARLESSO, Reimar. Déficit hídrico e os processos morfológico e fisiológico das plantas. Revista Brasileira de Engenharia Agrícola e Ambiental, v. 2, n. 3, p. 287-294, 1998. https://doi.org/10.1590/1807-

1929/agriambi.v2n3p287-294

SILVA, Lucas Augusto; LEITE, Manoel Reinaldo. Estimativa por sensoriamento remoto do comportamento da temperatura de superfície diante da conversão de Cerrado à Pastagem na bacia do Rio Jatobá no Norte de Minas Gerais. Geografia em Atos (Online), v. $1, \quad$ n. 5, p. 20, 2017. https://doi.org/10.35416/geoatos.v1i5.5240
SOBSTYL, J. M. et al. Role of City Texture in Urban Heat Islands at Nighttime. Physical review letters, v. 120, n. 10, p. 108701, 2018. https://doi.org/10.1103/PhysRevLett.120.10 $\underline{8701}$

SOUZA, L. B. Novas cidades, velhas querelas: episódios pluviais e seus impactos na área urbana de Palmas (TO), primavera-verão 2009/2010. Mercator, Fortaleza, CE, v. 9, n. Esp. 1, p. 165-177, dez. 2010.

TAIZ, L.; ZEIGER. Plant Physiology. California: The Benjamim Cummings Publishing Company, Inc., Redwood City, 1991.

THORNTHWAITE, C. W. An approach toward a rational classification of climate. Geographical Review, New York, v. 38, n. 1, p. 55-94, 1948. https://doi.org/10.2307/210739

THORNTHWAITE, C.W.; MATHER, J.R. The water balance. Centerton, NJ: Drexel Institute of Technology - Laboratory of Climatology, 1955. 104p. (Publications in Climatology, vol. VIII, n.1)

YAO, R. et al. Temporal trends of surface urban heat islands and associated determinants in major Chinese cities. Science of the Total Environment, v. 609, p. 742-754, 2017.

https://doi.org/10.1016/i.scitotenv.2017.07. $\underline{217}$

YOUNGSTEADT, E. et al. Responses of arthropod populations to warming depend on latitude: evidence from urban heat islands. Global change biology, v. 23, n. 4, p. 1436-1447, 2017. https://doi.org/10.1111/gcb.13550 